\title{
Örgütsel Kültür ve Alt Kültürün Örgütsel Bağlılığa Etkisi: Sağlık Çalışanları Üzerine Bir Araştırma
}

\author{
Çăgdaş Erkan AKYÜREK ${ }^{I^{*}}$, Şükrü Anıl TOYGAR ve Tolga ŞENER ${ }^{3}$ \\ ${ }^{I}$ Hacettepe Üniversitesi İ.I.B.F. Sağglk İdaresi Bölümü, Ankara, Türkiye \\ ${ }^{2}$ Gazi Üniversitesi İ.I.B.F. Sağllk Kurumları Issletmeciliği Bölümü, Ankara, Türkiye \\ ${ }^{3}$ Kırıkkale Üniversitesi Sağllk Hizmetleri Meslek Yüksek Okulu, Kırıkkale, Türkiye \\ 'e-mail:erkanakyurek52@hotmail.com
}

\begin{abstract}
Özet
Bu çalışmada örgüt kültürü, bürokratik, yenilikçi ve destekleyici olmak üzere üç boyutta ele alınmıştır. Buna ek olarak, hastanedeki örgütsel bağlllık seviyesinin tespit edilmesi ve bu çerçevede de örgüt kültürünün bu üç boyutunun örgütsel bağlllığa olan etkisini incelemek amaçlanmıștır. Araștırmanın evrenini Ankara ilindeki bir eğitim araștırma hastanesinde görev yapan 93 sağlık çalışanı (doktor, hemşire, idari personel) oluşturmaktadır. Çalışmada kullanılan veri seti Wallach tarafindan geliştirilen Örgüt Kültürü İndeksi ve Porter'ın Örgütsel Bağlllık Ölçeği olmak üzere iki bölümden oluşmaktadır. Bu çalıșmada kullanılan ölçeklerin Cronbach\&Alpha değerleri kabul edilebilir aralıkta bulunmuştur. Örgüt kültürünün bağlılığa olan etkisi destekleyici, bürokratik, yenilikçi olarak üç alt boyutta incelenmiş̦ir. Araştırma sonuçlarına göre örgüt kültürü alt boyutları sağlık çalışanlarının örgütsel bağlılıklarına ilişkin toplam varyansın \%34'ünü açıklamaktadır. Regresyon modelinde, regresyon katsayısının anlamlılığına ilişkin t-testi sonuçları incelendiğinde tek anlamlı ilişki örgüt külttüründe görülmüştür. Sağlık çalışanlarının destekleyici örgüt kültürü algıllamaları, örgütsel bağllıklarını istatistiksel olarak artırmaktadır.
\end{abstract}

Anahtar Kelimeler: Örgüt Kültürü, Bağll1ık, Sağlık Kurumları Yönetimi

\section{Organizational Culture and Subculture Effect on Organizational Commitment: A Research on Health Employees}

\begin{abstract}
This research has been held about the organizational culture and subculture effect on organizational commitment. The population of the research involves 93 health employees working at a Training and Research Hospital in Ankara (doctor, nurse and administrative stuff). The data set used for the research consists of two parts as Porter's Organizational Commitment Scale and Index of Organization Culture designed by Wallach. The Cronbach\&Alpha values of the scales used in this research is found to be in acceptable ranges. The effect of organization culture on commitment is analyzed under three sub - aspects as supporter, bureaucratic and improver. According to the research results, the sub - aspects of the organization culture explain $34 \%$ of the total variance concerning the organizational commitment of the health employees. As examining the t-test results about meaningfulness of regression factor in Regression model, the only meaningful relation is observed in organization culture. The perception of health employees about supportive organizational culture raises their organizational commitment statistically.
\end{abstract}

Keywords: Organizational Culture, Commitment, Healtcare Management

\footnotetext{
${ }^{1}$ Bu çalışma 6. Ulusal Sağlık ve Hastane İdaresi Kongresi’nde sözel bildiri olarak sunulmuştur.
} 


\section{Giriş}

Örgüt kültürü ve örgütsel bağl1lığa ilişkin çalışmaların özellikle son yıllarda artış gösterdiğini söylemek mümkündür. Rekabetin hızla arttığı ve iş görenin en önemli üretim faktörlerinden birisi olduğu günümüzde, işletmeler için iş gören tatmini en önemli verimlilik girdilerinden bir tanesi olarak değerlendirmektedir. İşgücü verimliliğinin sağlanmasında örgüt kültürünün ve iş gören bağlılı̆̆ının etkisi yadsınamaz bir gerçek olarak karşımıza çıkmaktadır. Profesyonelleşmenin en üst düzeyde yaşandığı hizmet işletmeleri olan sağlı kurumlarında da örgütsel bağlılık yöneticilerin en fazla üzerinde durduğu konulardan birisidir.

Bu çalışma, sağlık hizmeti üreten hastanelerdeki mevcut örgüt kültürünün örgütsel bağlllığa olan etkisini bürokratik, yenilikçi ve destekleyici olarak üç alt boyutta incelemiş ve örgüt kültürünün ne oranda örgütsel bağlılığı açıklayabildiğini ortaya koymak amacıyla yapılmıştır. Bu amaçla öncelikle örgüt kültürü ve örgütsel bağl1lık kavramları ele alınacak, sonrasında ise, Ankara ilindeki bir eğitim ve araştırma hastanesinde görev yapan 93 sağlık personeli üzerinde uygulanan ölçek sonuçları değerlendirilecektir.

\section{Örgüt Kültürü}

Kültür paylaşılan bir olgudur ve örgüt kültürü, paylaşımın örgüt seviyesinde gerçekleşmesi olarak ifade edilebilir (Brooks, 2003:241). Kurum ya da örgüt kültürü ise, yönetim yazarları tarafindan çeşitli şekillerde tanımlanmaktadır. Bununla birlikte bu tanımlamaların bir çoğu paylaşılan değerler, inançlar, varsayımlar, ilişki ve davranış kalıplarını içermektedir (Odom vd., 1990: 158). DuBrin (2005:294) ise örgüt kültürü kavramını çalışan davranışını etkileyen ortak değer ve inançlar bütünü olarak tanımlamantadır. Lahiry (1994: 50) de, Odom vd.(1990)'e ve DuBrin (2005)'e ek olarak örgüt kültürünün örgütte bulunan kişilere paylaşılan değerlere uyma konusunda baskı yaptığını ve kişilerin davranışlarını şekillendirdiğini belirtmektedir (Lahiry, 1994: 50).

Örgüt kültürü, çalışanların kendi örgütsel sorumluluk ve bağlılıklarını nasıl gördüklerine önemli ölçüde etki etmektedir (Chen, 2004: 432). Örgüt kültürü kısaca örgüt çalışanlarının örgütteki faaliyetlerin nasıl yapılacağına ilişkin paylaştıkları ortak anlayışları olarak ifade edilebilir (Wallach, 1983: 29). Makro açıdan bakıldığında, yani toplum kültürü düzeyinden bakıldığında ise, örgüt kültürü içinde bulunduğu toplumun bir alt kültürü olarak ifade edilebilir (Eren, 2010: 135). Hofstede ise "bir örgütün çalışanlarını, diğer işletmelerden ayıran niteliklerin bütünü” olarak tanımlamıştır (Hofstede, 2000:135).

Örgüt kültürü organizasyonlardaki kişilerin güçlerini etkilemektedir. Örgütsel güç sahipleri, onların dünya görüşlerinin ve halkla ilişkiler fonksiyonuna olan tavırlarının oluşturduğu yönetim felsefesi, organizasyon içindeki halkla ilişkiler rollerinin güçlü belirleyicileri olabilmektedir (Hong, 2003:12).

Örgütsel alt kültürün, örgüt kültüründen bağımsız olarak ve küçük bir grup halinde kendi değer, inanış ve davranış kalıplarına sahip olabildiği belirtilmektedir (Lok ve Crawford, 1999: 365). Odom vd. (1990: 157) 'ne göre, bir örgüt kültürünün yaygınlığı, o örgütteki yöneticilerin örgüt kültürü ve bu kültürün çalışanların memnuniyeti ve bağlığına olan etkisinin altında yatan boyutların tanımlanmasını gerektirmektedir. Örgüt kültürünün en açık etkilerinden birisi çalışanların davranışları üzerindeki etkisidir (Odom vd., 1990: 157). Diğer bir yandan, bir veya daha fazla alt kültür içeren bir kültüre de sahip olunabilmektedir. Örneğin dünyadaki bir çok sağlık örgütünde bir dizi alt kültür birbirleriyle iç içe çalışmaktadır. Doktorlar, hemşireler, tıbbi çalışanlar, yardımcı sağlık personeli ve müdürler, her biri farklı kültürel kimliklere sahiptirler ve her bir grup, örgütsel sembol anlayışlarını etkileyen, kendilerine özgü yorumlama sistemine göre çalışmaktadırlar (Brooks, 2003:241).

Wallach (1983) örgüt kültürünü bürokratik, yenilikçi ve destekleyici kültür olarak üç alt boyutta ele almıştır. Bürokratik kültürde güç ve kontrol, sorumluluk ve otorite açıkça tanımlanmakta ve sistemli bir yapı ve formalite etrafında konumlandırılmaktadır. Yenilikçi alt kültür ise değişim, girişimcilik, heyecan ve dinamizm gibi değerleri içerisinde barındırmaktadır. Bu iki alt kültüre ek 
olarak, destekleyici alt kültür de geniş bir aile ile uyumlu ilişkiler ve insani değerleri odak noktasına almaktadir (Wallach, 1983, 32-34).

Wallach (1983) bürokratik örgüt kültürlerinin hiyerarşik ve bölümlerden oluştuğunu, sorumluluk ve otorite çizgilerinin net olduğunu, işlerin organize edilmiş ve sistematik olduğunu belirterek, bu kültürlerin genellikle kontrol ve güce bağlı olduğunu ifade etmiştir. Destekleyici örgüt kültürüne sahip işletmeler ise çalışmak için sıcak ve karmaşık örgütler olup, çalışanlar ise arkadaş canlısı, dürüst ve yardımseverdir (Wallach, 1983:32).

Yenilikçi örgüt kültürünün hakim olduğu işletmeler incelendiğinde, yeniliği destekleyen bir kültürdeki organizasyonların çoğu kez müşteri odaklı, değer dürtülü ve stratejik olduğu göz çarpmaktadır. Bu tip örgütler, işletme stratejilerini çalışanlar, müşteriler, partnerler, satıcılar, tedarikçiler ve danışmanlar aracılığıyla geliştirmeye önem vermektedirler. Daha iyi rekabet edebilmek için neye ihtiyaç duyuyorlarsa bunun için kıyaslama yaparak pazar trendlerini yeniden incelemekte ve belirlemektedirler (Stanleigh, 2008:38).

\section{Örgütsel Bağlılık}

Bir kavram ve anlayış biçimi olarak bağlılık (commitment), "toplum duygusunun olduğu her yerde var olup, toplumsal içgüdünün duygusal bir anlatım biçimi" olarak ifade edilmektedir (Balay, 2000: 14). O’Malley (2000: 27), bağlılığın yaygın olarak yapılan tanımının "kişinin duygusal olarak bir durum karşısında kendisini zorunlu hissetmesi” olduğunu belirtmiştir. Carrel vd. (1997: 140)'ne göre örgütsel bağl1lık, örgüte katılan ve örgütten ayrılma konusunda gönülsüz kişilerin derecesini yansıtmaktadır. Çetin (2004: 90)'e göre ise örgütsel bağll1ık genel olarak işe katılma, sadakat ve örgüt değerlerine olan inanc1 da kapsayan bireyin örgüte olan psikolojik bağlılığını ifade etmektedir. Çalışanlar örgüte ne derecede bağlıysa, örgüt de o derecede güçlenmektedir (Çetin, 2004: 90). Macher (1988: 43), çalışanların bağl1lık seviyesini en yüksekten en düşüğe doğru yedi basamakta tanımlamıştır:

- Derin Bağlılık: Bu bağl1lık seviyesindeki çalışanlar işyerleriyle ilgili yüksek bir anlam ve amaç duygusuna sahiptirler. Bu durum kişisel hırslarının tamamen önüne geçmiştir ve farklılık yaratmak için çok çalışırlar.

- Kişisel Hırs: Bu kişiler sistemin nasıl işlediğini bilir ve bu doğrultuda kişisel hedeflerini gerçekleştirmek için yüksek seviyede gayret gösterirler (Macher, 1998: 43). Bu kişiler için kurum misyonunu gerçekleştirmek ikincil önemdedir (Sperry, 2003: 23).

- İlgili Fakat Sınırlı Güç Duygusu: Bu seviye bağl1lık düzeyindeki kişiler teknik anlamda yetkin, kalite kavramıla ilgili, ancak sistemin kurbanı olduklarına inanmaktadırlar (Macher, 1998: 43). Bu nedenle çabaları ve işlerine bağlılıkları sınırlıdır (Sperry, 2003: 23).

- Şekli Bağlılık: Çalıştıkları kurum arasında "şekli bağlılık" bulunan kişiler ancak kendilerine verilen görevleri yerine getirirler, daha fazlasını yapmaktan kaçınırlar (Macher, 1998: 43).

- Işsinde Gözlerden Uzak: Bu kişiler sorumluluktan ve iş yapmaktan kaçınırlar, kurum içerisinde kendilerini gizlerler (Macher, 1998: 43). Sürekli düşük performansları için bahaneler ileri sürerler. Zaman zaman harekete geçiyor gibi gözükebilirler ancak bu durumda bile düşük düzeyde bir başarı sağlayabilirler (Sperry, 2003: 23).

- Yabancılaşmış: Bu kişiler çalıştıkları kuruma, o kurumun çalışanlarına, müşterilerine karş1 hatırı sayılır derecede bir güvensizlik duymaktadırlar (Macher, 1988: 43). Kurumun misyonunu sabote etmek için açık eylemlerde bulunmasalar bile şikayet etme, boyun eğme ve en düşük seviyede performans standartlarını karşılama eğilimindedirler ve "nedensiz" olarak adlandırılırlar (Sperry, 2003: 24).

- Aktif Düşman: Bu kişiler bağlılığın en alt basamağını oluşturmaktadır. Yönetime ya da kuruma karşı aktif bir şekilde çalışırlar (Macher, 1988: 43). Onların tek bağlılı̆̆ı aldıkları ücret ve edindikleri faydalardir (Sperry, 2003: 24). 
Örgütsel bağlılık literatüründe bir çok farklı sınıflandırma bulunmaktadır. Bu çalışmada bunlardan dört tanesi ele alınacaktır.

Etzioni Sınıflandırması: Etzioni, örgütün iş gören üzerindeki güç veya yetkilerinin, iş görenin örgüte yakınlaşmasından kaynaklandığını (Gül, 2002: 40) ileri sürerek, örgütsel bağlılı̆̆ı, iş görenlerin örgüte bağlılıkları bakımından negatif (yabancılaştırıcı), nötr (hesapçı) ve pozitif (moral) bağlılık olmak üzere üç başlık altında incelemektedir. Negatif bağlllık, iş gören örgütü cezalandırıcı veya zararl1 gördüğü zaman meydana gelmektedir (Balay, 2000: 19). Pozitif bağlllık ise örgütsel hedefler, değerler ve normların içselleştirilmesinin sağlanmasına yönelik örgüte olan olumlu ve yoğun yöneliş olarak ifade edilebilir (Meyer ve Parfyonova: 2010: 284). Nötr bağlılığın temel felsefesi ise, iş gören ile örgut arasındaki alışveriş ilişkisine dayanmaktadır. Kişi kendisine verilen ücrete karşılık olarak bir günde çıkarılması gereken iş normuna uygun ölçüde bir bağl1lık göstermektedir.

Kanter Sınıflandırması: Kanter, örgüt tarafından iş görenlere empoze edilen davranışsal taleplerin, farklı bağl1lık türlerinin ortaya çıkmasına sebep olduğunu savunmaktadır. Bu talepler devam (continuance) bağl1lığı, kenetlenme (cohesion) bağl1lığı ve kontrol bağ l1lığı olmak üzere üç değişik bağl1lık oluşturmaktadır (Gül, 2002: 40). Devam bağl1lığında iş gören, örgüte fazlasıyla zaman ve çaba harcadığını, bunun sonucu olarak da örgütte kalmasının bir zorunluluk olduğunu düşünür. Bir başka deyişle kişiyi örgütte tutan faktör olası maddi kayıplardır (Çetin, 2004: 95) ve iş gören örgütten ayrılmanın maliyetinin farkındadır (Meyer ve Allen, 1991: 67). Kenetlenme bağlılığı, önceki sosyal ilişkilerden feragat veya grubun kenetlenmesini kolaylaştırıcı simge, sembol ve törenlere katılım gibi vasıtalar aracığıyla bir örgütteki sosyal ilişkilere bağlanma olarak ifade edilmektedir (Gül, 2002: 42). Kontrol bağl1lı̆̆1, iş görenin örgütün norm ve değerlerine olan içsel olarak bağlı olması olarak ifade edilebilir (Meyer ve Parfyonova, 2010: 284).

Allen ve Meyer Sınıflandırması: Allen ve Meyer, Kanter'in devam bağlılı̆̆ına paralel olarak örgütsel bağl1lığı duygusal, devam ve normatif bağl1lık olarak üç grupta ele almaktadır (Aslan, 2008a: 163). Meyer ve Allen duygusal bağlılık kavramını, işgörenlerin örgütle duygusal bir bağ kurmaları, örgüte dahil olmaları ve örgütle bir özdeşleşme yaşaması olarak tanımlamıştır. Güçlü bir duygusal bağl1lıkla örgütte çalışanlar, buna ihtiyaçları olduğu için değil bunu istedikleri için örgütte kalmaya devam etmektedirler (Meyer ve Allen, 1991: 67). Normatif bağll1ıkta ise iş görenler örgütte kalmasının gerektiği inancındadır (Çetin, 2004: 96), başka bir deyişle normatif bağlılık iş görenin örgütte kalma ile ilgili yükümlülük duygularını yansıtmaktadır (Balay, 2000:22).

Mowday Sınıflandırması: Mowday, bağlılı̆̆ı, tutumsal ve davranışsal bağlılık olarak iki şekilde ele almaktadır. Tutumsal bağl1lık, kişinin örgütsel amaçlarla özdeşleşmesini ve bunlar doğrultusunda çalışma isteği olarak ifade edilirken (Balay, 2000: 22) davranışsal bağlılık ise iş görenlerin bir örgüte ve örgütle ilgili problemlerle nasıl başa çıkacaklarına odaklanmaları süreciyle ilgilidir (Meyer ve Allen, 1991: 61).

\section{Yöntem}

\section{Araştırmanın Amacı}

Bu çalışma kapsamında örgüt kültürü bürokratik, yenilikçi ve destekleyici olmak üzere üç boyutta ele alınmıştır. Buna ilaveten hastanedeki örgütsel bağl1lık seviyesinin tespit edilmesi ve bu çerçevede de örgüt kültürünün bu üç boyutunun örgütsel bağl1lığa olan etkisini incelemek amacıyla yapılmıştır.

\section{Evren ve Örneklem}

Araştırma evreni olarak, verilerin daha sağlıklı toplanabilmesi amacıyla Ankara il merkezinde gerçekleştirilmiştir. Sağlık Bakanlığı'na bağlı bir eğitim araştırma hastanesinde doktor, hemşire ve idari personel olarak görev yapan 93 sağlık çalışanı (Araştırma evreninin \%37,6sı) araştırmanın evrenini oluşturmaktadır. 


\section{Veri Toplama Aracı}

Çalışmada kullanılan veri seti Wallach tarafindan geliştirilen Örgüt Kültürü İndeksi ve Porter'ın Örgütsel Bağl1lık Ölçeği olmak üzere iki bölümden oluşmaktadır. Araştırma kapsamında örgüt kültürü Wallach'ın (1983) bir çalışmasından uyarlanan ölçek ile değerlendirilmiştir. Ölçek, örgüt kültürünü her boyutta sekiz ifade olmak üzere bürokratik, yenilikçi ve destekleyici olarak üç alt boyutta toplam 24 ifade ile değerlendirmektedir. Ölçek 4'lü Likert tipinde " $0=\mathrm{Bu}$ iş yerinin özellikleriyle hiç bağdaşmıyor, $3=\mathrm{Bu}$ iş yerinin özellikleriyle büyük ölçüde bağdaşıyor" ş̧eklinde düzenlenmiştir. Ölçek Türkçeye Yahyagil (2004) tarafindan uyarlanmıştır. Bu çalışmada her bir alt boyut için Alpha katsayısı değerleri kabul edilebilir aralıkta bulunmuştur (bürokratik $=0.712$, yenilikçi=0.842, destekleyici=0.848). Örgütsel bağlılığın değerlendirilmesinde Porter vd. (1976) tarafindan geliştirilen ve Erigüç (1994) tarafından Türkçeye uyarlanan ölçek kullanılmıştır. Ölçek 7'li Likert tipinde (1= kesinlikle katılmıyorum, 7=kesinlikle katılıyorum) düzenlenen on beş ifadeden oluşmaktadır. Ölçeğin Alpha katsayısı 0.840 olarak hesaplanmıştır.

\section{Bulgular}

Tablo 1'de çalışmaya katılanlar personele ilişkin sosyo-demografik bulgular sunulmuştur.

Tablo 1. Sosyo-Demografik Bulgular

\begin{tabular}{|c|c|c|}
\hline Cinsiyet & Sayı (n) & Yüzde (\%) \\
\hline Erkek & 41 & 44.1 \\
\hline Kadın & 52 & 55.9 \\
\hline Medeni Durum & & \\
\hline Evli & 50 & 53.7 \\
\hline Bekar & 43 & 46.3 \\
\hline Yaş & & \\
\hline $18-25$ & 27 & 29.1 \\
\hline $26-35$ & 41 & 44.1 \\
\hline $36-45$ & 25 & 26.8 \\
\hline Meslek & & \\
\hline Doktor & 22 & 23.6 \\
\hline Hemşire & 40 & 43.1 \\
\hline İdari Personel & 31 & 33.3 \\
\hline Toplam & $\mathbf{9 3}$ & $\mathbf{1 0 0}$ \\
\hline
\end{tabular}

Tablo 2'de değişkenlerin aritmetik ortalama, min-max değerleri ve standart sapma değerleri verilmiştir. Buna göre örgüt kültürünün alt boyutlarından olan bürokratik kültür en yüksek ortalamaya sahiptir $(1,6344 \pm 0,60771)$.

Tablo 2. Aritmetik Ortalama ve Standart Sapma Değerleri

\begin{tabular}{|l|l|l|l|l|l|}
\hline Boyutlar & N & Min & Max & Ortalama & Ss \\
\hline Bağlılık & 93 & 1,73 & 5,93 & 4,1391 & 0,90685 \\
\hline Destekleyici & 93 &, 00 & 2,75 &, 9180 & 0,72431 \\
\hline Bürokratik & 93 &, 00 & 2,75 & 1,6344 & 0,60771 \\
\hline Yenilikçi & 93 &, 00 & 2,88 & 1,1586 & 0,53895 \\
\hline
\end{tabular}

Örgüt kültürü alt boyutlarının ortalamalarına bakıldığında, destekleyici alt kültürün en düşük ortalama puana sahip olduğu $(0,9180)$, en yüksek ortalama puana ise bürokratik alt kültürün olduğu $(1,6344)$ görülmektedir. Örgütsel bağlılık boyutunda ise ortalama puan 4,1391 olarak hesaplanmıştır. Örgütsel kültür alt boyutlarına ilişkin puan ortalamaları ile örgütsel bağl1lıklar arasındaki ilişkiyi ortaya koymak üzere uygulanan çoklu regresyon sonuçlarına göre oluşturulan regresyon modeline ait bütün tahminler modelin anlamlı ve kullanılabilir olduğunu göstermektedir $(\mathrm{F}=15,402 ; \mathrm{p}<0,05)$. 
Tablo 3. Regresyon Modeli

\begin{tabular}{|l|l|l|l|l|l|}
\hline Model & $\begin{array}{l}\text { Sum of } \\
\text { Squares }\end{array}$ & Df & $\begin{array}{l}\text { Mean } \\
\text { Square }\end{array}$ & F & Sig. \\
\hline 1 Regression & 25,856 & 3 & 8,619 & 15,402 &, $000^{\text {a }}$ \\
Residual & 49,803 & 89 &, 560 & & \\
Total & 75,659 & 92 & & & \\
\hline
\end{tabular}

Yapılan korelasyon analizi sonuçlarına göre bağl1lık ile destekleyici, bürokratik, yenilikçi alt kültürler arasında istatistiki olarak anlamlı ilişki olduğu tespit edilmiştir (Tablo 4).

Tablo 4. Korelasyon Analizi Sonuçları

\begin{tabular}{|ll|l|l|l|l|}
\hline & & Bağlılık & Destekleyici & Bürokratik & Yenilikçi \\
\hline Pearson Correlation & Bağlılık & 1,000 &, 571 &, 201 &, 439 \\
destekleyici & &, 571 & 1,000 &, 135 &, 742 \\
bürokratik & &, 201 &, 135 & 1,000 &, 296 \\
yenilikçi &, 439 &, 742 &, 296 & 1,000 \\
\hline Sig. (1-tailed) & Bağl1lık &. &, 000 &, 026 &, 000 \\
destekleyici & &, 000 &. &, 098 &, 000 \\
bürokratik & &, 026 & .098 &. &, 002 \\
yenilikçi & &, 000 & .000 &, 002 &. \\
\hline N & Bağl1lık & 93 & 93 & 93 & 93 \\
destekleyici & & 93 & 93 & 93 & 93 \\
bürokratik & & 93 & 93 & 93 & 93 \\
yenilikçi & & 93 & 93 & 93 & 93 \\
\hline
\end{tabular}

Araştırma sonuçlarına göre örgüt kültürü alt boyutları sağlık çalışanlarının örgütsel bağl11ıklarına ilişkin toplam varyansın \%34'ünü açıklamaktadır $\left(\mathrm{R}^{2}=0,342\right)$.

Tablo 5. Model Summary

\begin{tabular}{|l|l|l|l|l|}
\hline Model & R & $\mathbf{R}^{2}$ & Adjusted $\mathbf{R}^{\mathbf{2}}$ & Std. Error of the Estimate \\
\hline &, $585^{\text {a }}$ &, 342 &, 320 &, 74805 \\
\hline
\end{tabular}

${ }^{a}$ Predictors: (Constant), yenilikçi, bürokratik, destekleyici

Regresyon modelinde, regresyon katsayısının anlamlılı̆̆ına ilişkin t-testi sonuçları incelendiğinde tek anlamlı ilişki destekleyici örgüt kültüründe görülmüştür $(\mathrm{t}=4,401, \mathrm{p}<0,05)$.

Tablo 6. Çoklu Regresyon Analizi Sonuçları

\begin{tabular}{|l|l|l|l|l|l|}
\hline \multirow{2}{*}{ Model } & \multicolumn{2}{|l|}{$\begin{array}{l}\text { Unstandardized } \\
\text { Coefficients }\end{array}$} & $\begin{array}{l}\text { Standardized } \\
\text { Coefficients }\end{array}$ & & \\
\cline { 2 - 5 } & B & Std. Error & Beta & t & Sig. \\
\hline 1 (constant) & 3,209 &, 250 & & 12,836 &, 000 \\
Destekleyici &, 714 &, 162 &, 570 & 4,401 &, 000 \\
Bürokratik &, 196 &, 136 &, 131 & 1,443 &, 153 \\
Yenilikçi &,- 038 &, 226 &,- 023 &,- 169 &, 866 \\
\hline
\end{tabular}

a. Bağımlı değişken: bağlılık

Sağlık çalıșanlarının destekleyici örgüt kültürü algılamaları, örgütsel bağl11ıklarını istatistiksel olarak artırmaktadır. Her ne kadar regresyon analizi sonuçları örgütsel bağl1lıkla negatif bir ilişki gösterse de, yenilikçi örgüt kültürünün örgütsel bağlılık üzerindeki etkisi bağımsız olarak basit regresyon yöntemiyle incelendiğinde ve ikili korelasyon sonuçları göz önünde bulundurulduğunda, yenilikçi örgüt kültürünün örgütsel bağlılık üzerinde pozitif bir etkiye sahip olduğu bulunmuştur $(\mathrm{t}=4,664, \mathrm{p}<0.05)$. 
Tablo 7. Yenilikçi Kültür Basit Regresyon Analizi Sonuçları

\begin{tabular}{|l|l|l|l|l|l|}
\hline \multirow{2}{*}{ Model } & \multicolumn{2}{|l|}{$\begin{array}{l}\text { Unstandardized } \\
\text { Coefficients }\end{array}$} & $\begin{array}{l}\text { Standardized } \\
\text { Coefficients }\end{array}$ & & \\
\cline { 2 - 4 } & B & Std. Error & Beta & t & Sig. \\
\hline 1 (constant) & 3,283 &, 202 & & 16,228 &, 000 \\
Yenilikçi &,- 038 &, 226 &, 439 & 4,664 &, 000 \\
\hline
\end{tabular}

a. Bağımlı değişken: bağl1lık

\section{Tartışma ve Sonuç}

Literatürde örgütsel bağlılık ve örgüt kültürünü araştıran birçok araştırma bulunmaktadır. Chen (2004) tarafından bir araştırmada örgüt kültürü ile örgütsel bağlılığın arasında pozitif bir ilişki olduğu sonucu çıkmıştır.

Bağlılık, bir iş görenin çalıştığı kuruma verdiği önemi gösteren, geleceğe yönelik olarak hedeflerini belirleyen önemli bir faktör olarak karşımıza çıkmaktadır. Gowen III vd. (2006) tarafından yapılan bir araştırmada, kurumda bağlılığı artırmaya yönelik çalışmaların, çalışan bağ lılığını artırarak kaliteli hizmet sunulmasını sağladığını ortaya koymaktadır. Kurumsal bağlılı̆̆1 yüksek olan çalışanların daha kaliteli hizmet sunacakları söylenebilir. örgütsel bağlılığın çalışanların performansını, iș tatminini, örgütsel verimliliği artırdığ 1 ; ișe devamsızlığ 1 , personel devir hızını azalttı̆̆ı, çeşitli çalışmalarda ortaya konmuştur (Erdem, 2007:67). Türkiye'de yapılan görgül araştırmalarda örgütsel bağlılık ile çalışanların demografik özellikleri arasındaki ilişkileri inceleyen çalışmalarda (Özkaya vd., 2006; Yalçın ve İplik, 2005; Durna ve Eren, 2005) demografik özelliklerle örgütsel bağl1lık arasında genelde bir ilişkinin olduğu sonucuna varılmıştır

Örgütlerdeki baskın inanç ve varsayımlara odaklanan Aycan ve Kanungo (2000), çalışmalarında örgüt kültürünün profilini değiştirilebilirlik, proaktivite, yükümlülüklerini yerine getirme, sorumluluk isteme ve katılımcıl1k olarak belirlemişlerdir.

Örgütsel kültür ve alt kültürün örgütsel bağl1llğa olan etkisini araştırmak üzere yapılan bu çalışmada, örgütsel kültürün örgütsel bağlllık arasında pozitif bir ilişki olduğu ve örgütsel alt kültürler olan destekleyici, bürokratik ve yenilikçi alt kültürlerin örgütsel bağl1lığ $\% 34$ oranında açıkladığ1 sonucuna ulaşılmıştır.

\section{KAYNAKLAR}

Aslan, Ş. 2008. "Örgütsel Vatandaşlık Davranışı ile Örgütsel Bağl1lık ve Mesleğe Bağl11ık Arasındaki İlişkilerin Araştırılması" Yonetim ve Ekonomi Dergisi, 15 (2): 163-178.

Aycan, Z. ve Kanungo, R. 2000. "Toplumsal Kültürün Kurumsal Kültür ve İnsan Kaynakları Uygulamaları Üzerine Etkileri”, Aycan, Z. (der.) İçinde: Türkiye'de Yönetim, Liderlik ve İnsan Kaynakları Uygulamaları. Ankara: Türk Psikologlar Derneği Yayınları, 25-53.

Balay, R. 2000, Yönetici ve Öğretmenlerde Örgutsel Bağlılık. Ankara: Nobel Yayın Dağıtım.

Brooks, I. 2003. Organisational Behaviour- Individuals, Groups and Organisation. 2nd Ed. Essex: Prentice Hall.

Carrel, R. M., Jennıngs, R. D., Heavrın, C. 1997. Fundementals of Organizational Behavior, New Jersey: Prentice-Hall.

Chen, Y. L. 2004. Examining the Effect of Organization Culture and Leadership Behaviors on Organizational Commitment, Job Satisfaction, and Job Performance at Small and Middle-sized Firms of Taiwan, The Journal of American Academy of Business, Cambridge, September, ss:432-438.

Çetin. O. M. 2004. Örgüt Kültürü ve Örgütsel Bağl111k. Ankara: Nobel Yayın Dağıtım.

Dubrin, A. J. 2005. Fundamentals of Organizational Behavior. Ohio: South-Western College Pub. 
Durna, U. ve Eren, V. 2005. “Üç Bağlılık Unsuru Ekseninde Örgütsel Bağl1lık”, Doğuş Üniversitesi Dergisi, $6(2), 210-219$.

Erdem, R. 2007. "Örgüt Kültürü Tipleri ile Örgütsel Bağl1lık Arasındaki İlişki: Elazığ Il Merkezindeki Hastaneler Üzerinde Bir Araştırma”, Eskişehir Osmangazi Üniversitesi İ̈BF Dergisi, 2 (2): 63 79.

Eren, E. 2010. Örgütsel Davranış ve Yönetim Psikolojisi. 12. Baskı. İstanbul: Beta Yayınları.

Erigüç, G. 1994. Hastanelerde Personelin İşle İlgili Tutumları Personel Devri: Ankara İli Örneği, Hacettepe Üniversitesi Sağlık Bilimleri Enstitüsü Yayınlanmış Doktora Tezi.

Gowen III, R. C., Mcfadden, L. K., Hoobler, M. J., Tallon, J. W., (2006), "Exploring the Efficacy of Healthcare Quality Practices, Employee Commitment, and Employee Control" Journal of Operations Management, 24, ss: 765-778.

Gül, H. 2002. "Örgütsel Bağlılık Yaklaşımlarının Mukayesesi ve Değerlendirmesi” Ege Akademik Bakış Dergisi, 2 (1): 37-56.

Hofstede, G. 2000. Organizational Culture: Siren or Sea Cow? A reply to Dianne Lewis. Strategic Change, Vol. 9, s.135-137.

Hong, Y. 2003. "Influence of Culture on Public Relations Practitioner Roles: A Cross-National Comparative Study, The U.S. and Sorth Korea", Thesis (M.A.), California State University, USA.

Lahiry, S. 1994. "Building Commitment Through Organizational Culture", Training and Development, Vol. 3, pp. 50-2.

Lok, P. ve Crawford, J. 1999. The Relationship Between Commitment and Organizational Culture, Subculture, Leadership Style and Job Satisfaction in Organizational Change and Development. Leadership\& Organization Development Journal (20): 7: 365-373.

Macher, K. 1988. "Empowerment and The Bureaucracy", Training Development Journal, September, p.:41-45.

Meyer, J. P., Allen, J. N. 1991. A Three Component Conceptualization of Organizational Conception, Human Resources Management Review, 1 (1): 61-89.

Meyer, J. P., Parfyonova, N. M. 2010. "Normative Commitment in The Workplace: A Theoretical Analysis And Re-Conceptualization", Human Resource Management Review 20: 283-294.

Odom, Y. R., Boxx, R. W., Dunn, G. M. 1990. Organizational Cultures, Commitment, Satisfaction and Cohesion. Public Productivity \& Management Review, 14 (2): 157-169.

O'Malley, M. 2000. Creating Commitment: How to Attract and Retain Talented Employees by Building Relationships That Last. New York: John Wiley\&Sons.

Özkaya, M.O., Kocakoç, İ. ve Kara, E. 2006. "Yöneticilerin Örgütsel Bağlllıkları ve Demografik Özellikleri Arasındaki İlişkileri İncelemeye Yönelik Bir Alan Çalışması”, Celal Bayar Üniversitesi İ.İ.B.F. Yönetim ve Ekonomi Dergisi, 13 (2): 76-96.

Sperry, L. 2003. Becoming An Effective Health Care Manager: The Essential Skills of Leadership. Health Professions Press, Baltimore.

Stanleigh, M. 2008. "Guide to Innovation”, Industrial Engineer, 40 (6): 38-41.

Yalçın, A. ve İplik, F.N. 2005. "Beș Yıldızlı Otellerde Çalışanların Demografik Özellikleri İle Örgütsel Bağlllıkları Arasındaki İlişkiyi Belirlemeye Yönelik Bir Araştırma: Adana

Wallach, J. E. 1983. Individuals and Organizastions: The Cultural Match, Training and Development Journal, February, s. 29-36. 